\title{
Hard scalp lump with headache
}

\author{
Rita Momjian • Mahmoud Saber • Mina George
}

Published online: 17 August 2014

(C) ISS 2014

\section{Test Yourself: Question}

Hard scalp lump with headache

A 53-year-old woman presented with a left-sided hard scalp lump of about 1 year duration; it had gradually increased in size and was associated with recurrent mild headache. There was no history of trauma, and the medical history was unremarkable. There were no neurological deficits (Figs. 1, 2 and 3).

Fig. 1 CT of the head (axial sections). a Brain window. b Bone window

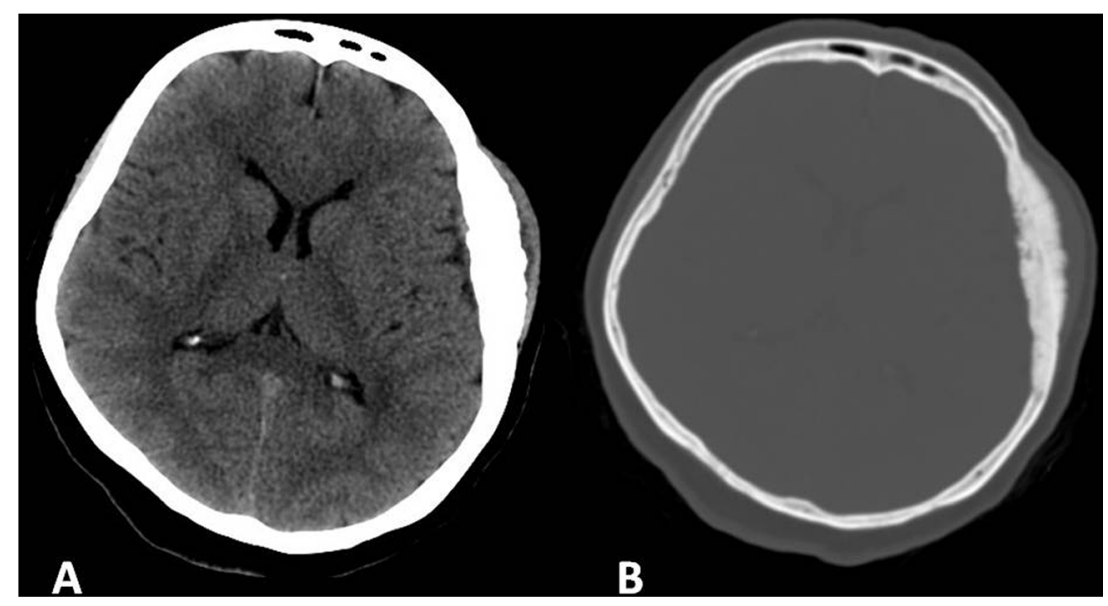

The diagnosis can be found at doi: 10.1007/s00256-014-1985-4

R. Momjian $(\bowtie) \cdot$ M. Saber

Department of Radiology, Khoula Hospital, PO Box 90, 116

Mina-al-Fahal, Muscat, Sultanate of Oman

e-mail: ritamomjian@yahoo.com

M. George

Department of Histopathology, Khoula Hospital, Muscat, Sultanate

of Oman 
Fig. 2 MRI of the brain. a Axial T1-weighted image. b Axial T2weighted image

Fig. 3 Histopathological photomicrographs (hematoxylin and eosin stain). a Low power view $(\times 20)$. b Higher power view $(\times 40)$
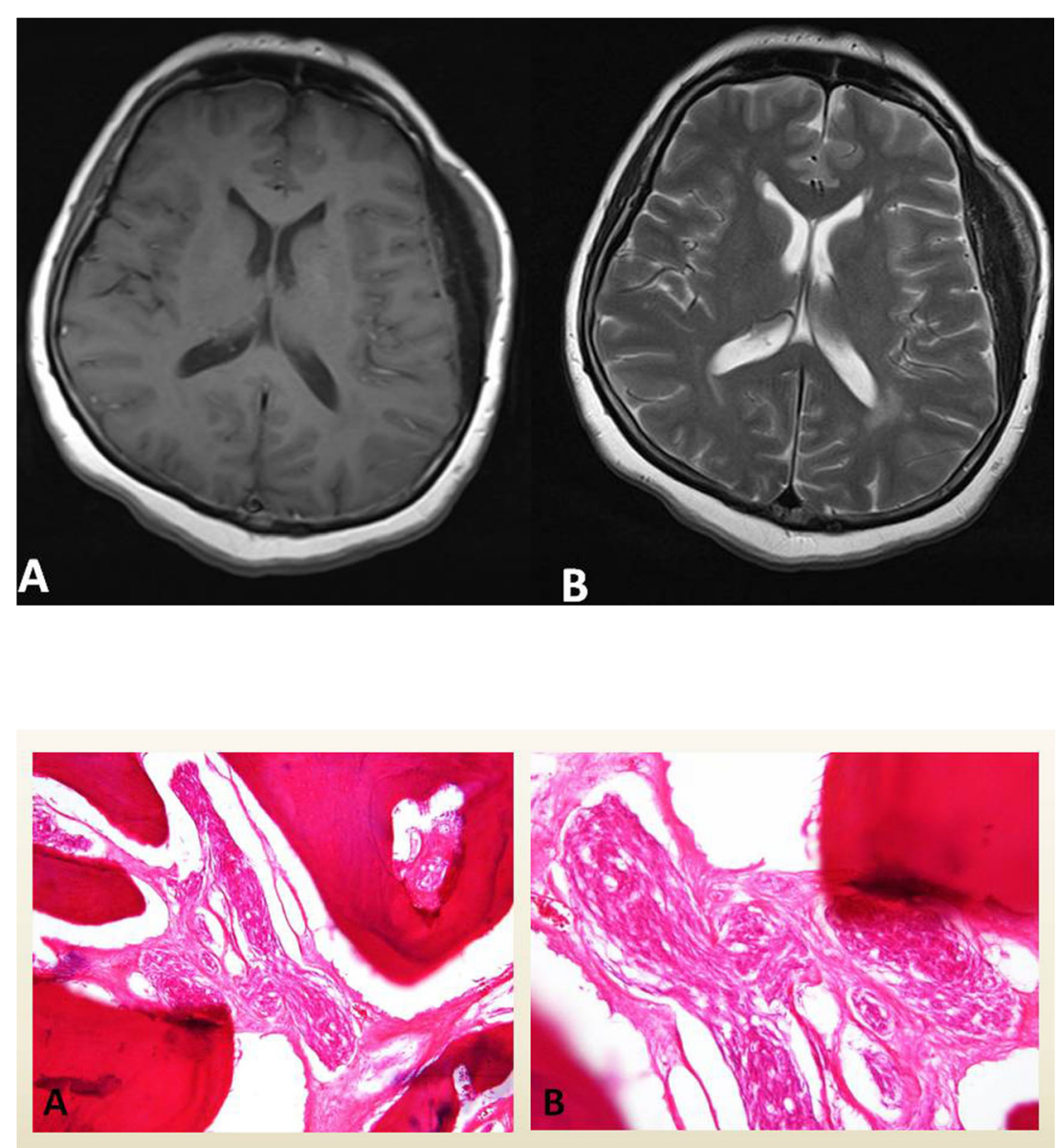

Statements The contents of this manuscript have not been published previously in whole or in part or submitted elsewhere for review.

Contributors This work is written by RM and MS with full support of MG.
Competing interests None 